\title{
The Fact of Evolution: Implications for Science Education
}

\author{
JAMES R. HOFMANN ${ }^{1}$ and BRUCE H. WEBER ${ }^{2}$ \\ ${ }_{1}^{1}$ Philosophy Department, California State University Fullerton, PO Box 6868, Fullerton CA \\ 92834-6868, USA (E-mail: jhofmann@fullerton.edu); ${ }^{2}$ Bennington College, Bennington, VT 05201 \\ USA, and Department of Chemistry and Biochemistry, California State University Fullerton, \\ Fullerton, CA 92834-6866USA (E-mail: bweber@bennington.edu)
}

\begin{abstract}
Creationists who object to evolution in the science curriculum of public schools often cite Jonathan Well's book Icons of Evolution in their support (Wells 2000). In the third chapter of his book Wells claims that neither paleontological nor molecular evidence supports the thesis that the history of life is an evolutionary process of descent from preexisting ancestors. We argue that Wells inappropriately relies upon ambiguities inherent in the term 'Darwinian' and the phrase 'Darwin's theory'. Furthermore, he does not accurately distinguish between the overwhelming evidence that supports the thesis of common descent and controversies that pertain to causal mechanisms such as natural selection. We also argue that Wells' attempts to undermine the evidence in support of common descent are flawed and his characterization of the relevant data is misleading. In particular, his assessment of the 'Cambrian explosion' does not do justice to the fossil record. Nor do his selective references to debate about molecular and paleontological phylogenies constitute a case against common descent. We conclude that the fossil and molecular evidence is more than sufficient to warrant science educators to present common descent as a well-established scientific fact. We also argue that diagrams depicting the 'tree of life' can be pedagogically useful as simplified representations of the history of life.
\end{abstract}

\section{Introduction}

Scientists have reached overwhelming consensus that all forms of life are related by common descent. To give students a rough idea of what this means, one common pedagogical strategy is to call their attention to the relationships they see within their own extended family. For example, each student has ancestors in common with any cousin that student might have, namely, two of their grandparents. Similarly, a first approximation to the idea of common descent is to say that any two species of life have an ancestral species in common, albeit many more generations in the past than the two generations that separate two cousins from their grandparent. As we will see, like all analogies, this one has limitations and does not apply very well to the early stages of the history of life. Nevertheless, students' knowledge of their own family trees can serve as a useful starting point for understanding common descent, an idea scientists often refer to as 'the tree of life'. 
In marked contrast to the scientific community, opinion polls consistently show that the idea of common descent is still controversial for a significant percentage of the general United States population (Alters \& Nelson 2002, p. 1892). Consequently, it is not surprising that decisions about American public school science curricula often are contentious. While opinion polls show that many religious people accept common descent, those creationists who harbor religious objections sometimes try to influence school board decisions by citing publications that have not been subjected to the usual process of scientific peer review. In this essay we address one such publication, Jonathan Wells' Icons of Evolution (Wells 2000), a book that has received uniformly negative reviews by scientists from a wide variety of disciplines (Padian \& Gishlick 2002; Scott 2001; Pigliucci 2001; Coyne 2001; Ussery 2001; Raff 2001; Rudge 2002).

We focus our critique on the third chapter of Icons, 'Darwin's Tree of Life', the chapter Wells devotes to the notion of common descent. Based on this chapter, Wells uses an appendix to "grade" science textbooks according to their discussion of 'universal common ancestry'. Wells gives progressively poor grades depending upon how straightforwardly a textbook presents the scientific consensus that common descent is a 'fact'. Indeed, of the ten books Wells grades, he gives a grade of ' $F$ ' to eight and ' $D$ ' to the remaining two. We argue that this assessment is misguided and that Wells has not advanced any refutation of common descent in the chapter he devotes to the subject. Based upon a multitude of many forms of evidence, the thesis of common descent is not controversial within the scientific community; science educators should be assured that Wells' attempt to influence science curricula by sidestepping the usual scientific peer review process should not be given any credence. Although scientists marshal many types of evidence in support of common descent, we concentrate on the two that Wells claims are lacking: the fossil record and the molecular evidence. As a prelude, we clarify the distinction between the idea of common descent and theoretical efforts to explain how this process has come about.

\section{Fact and Theory}

Before looking at specific arguments, we need to clarify some conceptual and philosophical issues pertaining to the relationship of facts to theories and various usages of the terms 'evolution' and 'Darwinism'.

\subsection{DEDUCTION AND INDUCTION}

Unfortunately, there is a widespread misconception among students that when scientists refer to 'facts' they mean assertions that have been 'proved' in the deductive sense. Strictly speaking, this is never the case. Deductive 'proof' is indeed accomplished in the disciplines of mathematics and logic, but only by employing axiomatic idealizations irrespective of any relationship to physical reality. In these 
domains deductive proof is the norm; conclusions are deduced or derived with absolute certainty by applying rules of inference to definitions and axioms. Euclidean geometry is an example well known to many students. Once geometric definitions and axioms are stipulated, theorems can be proved unambiguously.

In sharp contrast to formal logic and mathematics, scientific reasoning typically assesses inductive evidence in support of hypothetical propositions. Hypotheses are tentatively proposed to account for a particular collection of data. The amount of supportive evidence for the hypothesis depends upon the scope of this data as well as the confirmed new implications or predictions that follow from the hypothesis. Nevertheless, no matter how extensive this inductive evidence becomes, the result is never deductive 'proof' in the mathematical or logical sense. Inductive evidence accumulates in degrees but never achieves certainty in the deductive sense. In an effort to disassociate the term 'fact' from its vernacular connotation of absolute certainty, Stephen Jay Gould has proposed that a scientific fact is an assertion that has been "confirmed to such a degree that it would be perverse to withhold provisional assent" (Gould 1983, p. 255).

There is much to be said for Gould's pithy gloss. It captures the idea that there is no objective manner of determining the exact point at which inductive evidence becomes sufficient to conclude that a hypothetical claim should be accepted as 'fact'. As in a jury trial, a judgment call determines when the evidence is sufficient to convict. Scientific facts are not claims that have been 'proved' the way mathematical theorems are proved on the basis of axioms and rules of inference. They are assertions with enough inductive evidence supporting them that the relevant scientific community no longer has reason to question them.

\subsection{DATA AND PHENOMENA}

In an educational context, it is also important for students to understand that scientific facts have a wide range in complexity. Although all factual claims are attempts to describe some aspect of reality, some of these factual statements are more complicated and controversial than others. For example, to claim that some sand is brown is less controversial than to assert that the earth is approximately 90 million miles from the sun. Nevertheless, each of these claims is factual and each has been sufficiently supported by evidence to the point that each would be described by a scientist as a 'fact'. To explore the taxonomy of scientific facts in more detail, consider planetary motion, observed and speculated about for millennia. Data pertaining to planetary positions are the result of fairly straightforward observations. Early in the seventeenth century, Kepler used these data to infer the more complicated facts we now refer to as Kepler's laws. Namely, Kepler proposed that the planets follow elliptical orbits around the sun, sweep out equal areas in equal periods of time and have the square of their orbital period proportional to the cube of their average distance from the sun. The counter-intuitive nature of these claims made them controversial in the seventeenth century; nevertheless, to 
use Gould's phrase, they now have been "confirmed to such a degree that it would be perverse to withhold provisional assent" (Gould 1983, p. 255). Irrespective of public opinion, they are accepted by scientists as non-controversial facts.

Understanding the distinction between what Kepler observed and the more complicated facts he inferred from his observations is a useful prelude to understanding an analogous but more complicated distinction within evolutionary biology. Primarily drawing upon examples from physics, philosophers of science James Woodward and James Bogen have characterized this distinction as a contrast between data and phenomena (Bogen \& Woodward 1988; Woodward 1989). Kepler's data were specific observations of planetary locations at specific times. From these direct observations he inferred that the planets follow elliptical orbits around the sun, sweep out equal areas in equal periods of time and have a specific relationship between their solar periods and average solar distances. In sharp contrast to the data Kepler had at his disposal, these three factual assertions do not refer to any aspect of planetary motion that can be directly observed. While some scientific facts are the result of direct observations, others are inferred from observational data. In the latter case, Bogen and Woodward have argued that it is useful to refer to these inferred facts as 'phenomena'. Using this rubric, both the observations Kepler relied upon and the inferences he drew from those observations now are uniformly acknowledged scientific 'facts'; the former are Kepler's data and the latter are the phenomena he inferred from those data, the well known 'Kepler's Laws'.

Although Bogen and Woodward initially applied their distinction between data and phenomena to cases in physics and psychology, it has proved useful in solid state chemistry and hydrology as well (Hofmann 1990; Hofmann \& Hofmann 1992). We argue that it is also pertinent to evolutionary biology. Before we do so, an additional very important philosophical issue must be addressed. With the hierarchical, tentative, and fallible nature of scientific factual claims in mind, how do theoretical explanations relate to these empirical facts, facts which include both data and phenomena? Implicit in this question is the issue of how scientific facts differ from scientific 'theories'.

\subsection{THEORETICAL EXPLANATION}

Although the notion of scientific explanation is still a lively subject of philosophical debate, and the detailed nature of scientific explanation does indeed vary from one science to another, there is a general consensus among both philosophers and scientists that the function of theoretical statements and theories is to explain rather than to describe (Salmon 1992). That is, scientific theories provide explanations for why the empirical facts are as they are. For example, while Kepler's laws state three facts about planetary motion, Newton's theory of gravitation was the first theory to accurately explain why the planets conform to Kepler's laws. Using his formulation of a universal gravitational force, Newton showed that when an inverse 
square attractive gravitational force is applied to an idealized two-body system made up of the sun and a planet, the planet will obey Kepler's laws as it orbits the sun. Little confusion between fact and theory arises in this case due to the clear distinction between the primarily descriptive nature of Kepler's factual laws and the explanatory nature of Newton's theory. For example, Kepler's first law simply states the fact that the planets follow elliptical orbits; Newton's theory of gravitation explains why this phenomenon takes place.

\subsection{THE FACT OF EVOLUTION}

When we turn to evolutionary biology, the situation is more complicated. The relevant data include fossil evidence, genetics, a wide variety of molecular sequence data, biogeography, embryology, comparative anatomy, and developmental biology, to cite just some of the pertinent sources. Although this list was shorter in Darwin's day, he nevertheless was confronted with a daunting collection of complex data. How did Darwin respond and in what respects was his response analogous to Kepler's conclusions about planetary data? First of all, Darwin argued that the data support the hypothesis that any two forms of life share a common ancestor, an hypothesis he referred to as 'descent with modification'. In one respect, this proposal is analogous to Kepler's conclusion that planetary data imply that planets follow elliptical orbits. In both cases, a more complex fact, a phenomenon, is inferred from simpler and directly observable data. In general, descent with modification or common descent is the phenomenon biologists have in mind when they assert that 'evolution is a fact'. Indeed, there is as little dispute about this fact among biologists as there is dispute about Kepler's laws among astronomers. As a first approximation, the factual claim of common descent can be stated metaphorically by saying that all life constitutes a 'family tree'. The inspiration for this usage is the personal knowledge many people have about their own ancestry. Family reunions often are occasions for determining common shared ancestors and relevant lineages. This idea of lineages does introduce a complication. For example, even though two cousins might agree that they share a common ancestral grandfather, they might disagree about what lineage connects each of them to that grandfather. That is, each of them may wonder who among their grandfather's offspring was their parent. Similarly, debate about evolutionary pathways is to be expected since the idea of common descent allows for many alternative paths for that descent. This issue has an analogue in the case of planetary motion in the sense that many different elliptical orbits are compatible with Kepler's laws. So in one respect, the phenomenon of common descent does have a strong analogy to the facts expressed by Kepler's laws. In both cases a large collection of data is the basis for an inference to a more complicated factual assertion.

Nevertheless, there is another facet to the phenomenon of common descent that is not so analogous to the astronomy case. Kepler's first law simply describes planetary motion by asserting that planets follow elliptical orbits. Common descent 
is a historical claim about the past. In this respect it is an attempt to make sense of historical data in the same way that a jury tries to reach a verdict that makes sense of forensic evidence. An indictment is a hypothesis that a particular suspect is guilty of a crime. When a jury decides that the evidence is sufficient to convict the suspect, there is a sense in which that conviction does more than simply make a factual claim; it also explains why the evidence is as it is. Is there an analogously explanatory aspect to the hypothesis of common descent?

Philosophers do enjoy making fine distinctions. Following Woodward and Bogen, it can be argued that the common descent hypothesis does not explain why any specific piece of evidence is precisely how it is. For example, common descent per se does not fully explain why a particular horse fossil has the detailed structure that it has or why it was found in a specific rock formation. Nevertheless, from a broader perspective, the thesis of common descent does explain why the fossil record has patterns that include horse fossils in some times and places and not others (Ruse 2000; Pennock 1999, pp. 284-294). It was this explanatory aspect of the idea of common descent that prompted Darwin himself to sometimes refer to his "theory of descent with modification".

Science educators thus are burdened by difficult ambiguities. Biologists overwhelmingly accept the assertion of common descent as a scientific fact, an assertion that has been "confirmed to such a degree that it would be perverse to withhold provisional assent" (Gould 1983, p. 255). At the same time, common descent also has explanatory power; it brings a wide range of data from many disciplines within one conceptual umbrella. For example, why do we find such extensive correlation between paleontological and molecular data? The thesis of common descent provides an answer to this question. Species that are widely separated via molecular data would be expected to have a common ancestor relatively early in the fossil record because all life constitutes a family tree and some species are less closely related to each other than others.

Unfortunately, because of this explanatory component of the fact of common descent, some anti-evolutionary advocates try to introduce inappropriate revisions into science curricula by promulgating the slogan that evolution is 'only a theory'. Science educators should not be duped by this stratagem. Although acceptance of the fact of common descent does provide an explanation for a multitude of data, this should not in any manner obscure student understanding that common descent is indeed a fact. Some paleontological and molecular arguments in support of common descent will be summarized later in this essay.

To make matters more complicated, Darwin went on to play a role analogous to that of Newton by proposing an explicitly explanatory theory, Darwin's theory that the primary mechanism responsible for common descent is natural selection. That is, Darwin offered an explanation for why common descent pertains to all life; natural selection acting on variations within all species causes diversification into the "tree of life". The word 'evolution' thus is deeply ambiguous. Sometimes it may refer to the primarily factual claim of common descent. In other contexts, it 
may refer either to Darwin's explanatory theory based upon natural selection or to modern expansions of Darwin's theory, the neo-Darwinian synthesis of natural selection and genetics. Thirdly, the term 'evolution' may also refer to one or another segment, subset or lineage within the incredibly complex set of relationships subsumed under the term 'common descent'. In any case, students need to recognize that whether or not Darwin's theory or neo-Darwinian theory is a good explanation, common descent remains the fact that these theories are intended to explain.

\subsection{THE AMBIGUITIES OF 'EVOLUTION' AND 'DARWINISM'}

In most pedagogical contexts, one of the most important ambiguities to resolve is the difference between the factual claim of common descent and explanatory theories that include and expand upon Darwin's reliance upon natural selection. There is some irony associated with this particular ambiguity. Both Michael Denton and Michael Behe, for example, are well known for their criticism of natural selection as a mechanism for evolutionary change. They are widely cited in support of a variety of anti-evolutionary positions. Nevertheless, neither man objects to the fact of common descent. In the opening chapter of his book Darwin's Black Box, Behe comments that: "Further, I find the idea of common descent (that all organisms share a common ancestor) fairly convincing, and have no particular reason to doubt it" (Behe 1996, p. 5).

Similarly, Denton writes that:

The reason why no current member of the US National Academy of Science is a special creationist is because of the facts, the same facts that in the nineteenth century convinced Darwin and Wallace and all the leading Christian biologists, including Joseph Hooker, Asa Gray, and Charles Lyell, of the reality of descent with modification. (Denton 1999, p. 154)

Actually Denton's assertion is an understatement since there is considerably more evidence available now than was the case in the nineteenth century. Before turning to that evidence, we should address the rhetoric that utilizes the terms 'Darwinism' and 'Darwinist'.

These terms can be used in a benign manner simply to refer to the arguments advocated in the nineteenth century by Charles Darwin. In this sense, 'Darwinist' arguments are those of Darwin himself and they can be assessed through a combination of historical research and modern science. Unfortunately, there are all too many misleading usages of the term 'Darwinist' that ascribe materialistic and atheistic convictions to scientists who simply advocate either some version of neo-Darwinian theory or accept the fact of common descent. To cite one example, Phillip Johnson introduces these terms in the first few pages of his anti-evolutionary polemic Darwin on Trial. In an introductory passage of his first chapter he writes:

Evolution is taught in the public schools (and presented in the media) not as a theory but as a fact, the "fact of evolution". There are nonetheless many dissidents, some with advanced scientific degrees, who deny that evolution is a fact and who insist that an intelligent Creator caused all living things to come into being in furtherance of a purpose. (Johnson 1993, p. 3) 
What does Johnson mean by 'evolution' in this passage? The two most obvious possibilities are common descent and neo-Darwinian theory. But it turns out that Johnson has a third option in mind. He correctly notes that: "Evolution" contradicts "creation" only when it is explicitly or tacitly defined as fully naturalistic evolution - meaning evolution that is not directed by any purposeful intelligence' (Johnson 1993. p. 4). He then uses a footnote to introduce the term 'Darwinism' to mean 'fully naturalistic evolution, involving chance mechanisms guided by natural selection' (Johnson 1993, p. 4). Throughout the rest of his book Johnson employs the terms 'Darwinist' and 'Darwinism' in such a manner as to include not only common descent and neo-Darwinian theory, but materialism and atheism as well, a position he calls the 'blind watchmaker thesis'. Furthermore, the version of neoDarwinian theory he addresses is a particularly extreme version of gradualism and adaptationism. 'Darwinism' in Johnson's lexicon thus means far more than the factual claim of common descent. His strategy is to generate doubt about 'Darwinism' as he has characterized it and hope that this doubt will extend to common descent as well. In light of the widespread reliance upon Darwin on Trial within creationist circles, it is not surprising that Johnson's strategy has been adopted by other anti-evolutionary writers.

One of these authors is Jonathan Wells, the subject of the present essay. Following Johnson's lead, Wells introduces as his target the position he terms 'Darwinian evolution'. He does so in a misleading manner. In the introduction to his book he writes: 'Biological evolution is the theory that all living things are modified descendents of a common ancestor that lived in the distant past' (Wells 2000, p. 4). Tucked within this statement is a phrase that is a reasonable paraphrase of common descent: 'all living things are modified descendents of a common ancestor'. But as we have argued at some length, the notion of common descent is not simply a 'theory' of biological evolution; it is primarily a factual claim, not a theoretical explanation. Wells compounds this confusion in a subsequent paragraph that is worth quoting in full.

No one doubts that descent with modification occurs in the course of ordinary biological reproduction. The question is whether descent with modification accounts for the origin of new species - in fact, of every species. Like change over time, descent with modification within a species is utterly uncontroversial. But Darwinian evolution claims much more. In particular, it claims that descent with modification explains the origin and diversification of all living things. (Wells 2000, p. 5)

Contrary to what Wells claims, descent with modification, as evolutionary scientists use the term, does not 'account for' the origin of each and every species. At most, descent with modification refers to a temporally bounded lineage within the more complex phenomenon of common descent. It is primarily a factual description, not an explanation of why the tree of life has the shape that it does.

Wells goes on to claim that 'Darwinian evolution' has a foundation consisting of a few paradigmatic examples. 'When asked to list the evidence for Darwinian evolution, most people - including most biologists - give the same set of examples, because all of them learned biology from the same few textbooks' (Wells 2000, p. 
6). As the second 'icon' on his list, Wells enters 'the evolutionary tree of life, reconstructed from a large and growing body of fossil and molecular evidence' (Wells 2000, p. 6). But as we will argue in detail, the 'evolutionary tree of life' is simply an idealized representation of the fact of common descent and is not intended to be 'evidence for Darwinian evolution'. Wells thus has thoroughly misrepresented the actual relationships that hold between the evidence for common descent, common descent itself, and evolutionary theory as it has developed from the time of Darwin. Before looking at his critique in more detail, we should briefly review two categories of this evidence.

\section{Evidence for Common Descent}

Writing in 1859, Darwin relied upon several types of inductive evidence to support his claim that common descent is a fact of life (Darwin 1859). The fossil record, the geographic distribution of modern species and data drawn from comparative anatomy were all important sources. Of course the most significant modern types of evidence not available to Darwin come from genetics and molecular sequence analysis. For present purposes we focus on fossil evidence and some of the molecular data.

\subsection{THE FOSSIL EVIDENCE}

Although it often becomes a topic of discussion when creation and evolution are debated, the overall structure of the fossil record lends strong support to the hypothesis of common descent. The various forms of life obviously are not arbitrarily distributed among the geological strata. On the contrary, as was know even in Darwin's time, there is a complex structure to the fossil record. Every textbook on evolution appropriately includes a diagram showing the correlation of geological formations with examples of taxa that have fossilized in them (Futuyma 1998). It is of course impossible to establish with certainty that one fossil represents a direct ancestor of another; nevertheless, the general message of the fossil record is that it is a historical record of a complex web of relationships.

Although the exact origin of life remains unknown, the oldest known fossils are simple bacteria-like prokaryotes or cynobacteria found in pre-Cambrian rocks about 3.8 billion years old. During the subsequent three billion years, the fossil record gradually becomes more complex. There is evidence of single-celled eukaryotic life, algae, as far back as 1.4 billion years ago and more extensive evidence of eukaryotic life about 900 million years ago. Trace fossils of animal life have been found dating back to slightly less than one billion years ago. The oldest fossils of multicellular animals are in rocks 640 million years old.

Classification and analysis of the subsequent fossil record is inevitably influenced by our knowledge of existing life. For example, modern animals are classified in approximately thirty-five groups, each with a different body plan. 
About half of these thirty-five phyla have a fossil record that traces their origins back at least as far as the beginning of the Cambrian, 543 million years ago (Raff 1996, p. 175). Some researchers speculate that all thirty-five existing animal phyla had origins at least that early (Raff 1996, p. 95). Extensive trace fossils and animal phyla such as Cnidaria (including jellyfish) and Porifera are found in the immediately pre-Cambrian Ediacaran formation (Carroll et al. 2001, pp. 2-5). There presently is little consensus about the exact lineages that link pre-Cambrian life to later forms. This is a fascinating area of research where hypotheses are not well enough established to be presented in elementary textbooks. Fossil diversity increases far more rapidly throughout the subsequent 45 million years of the Cambrian period. This remarkable surge in diversity has been labeled the 'Cambrian explosion'; in due course we will discuss the flaws in Wells' efforts to use the Cambrian explosion as evidence against common descent.

The fossil record subsequent to the Cambrian provides overwhelming evidence that animal life continued to develop into forms that we can recognize as increasingly modern. The University of California at Berkeley has posted an interesting display of when the various phyla appear. It can be found at http://www.ucmp.berkeley.edu/phyla/metazoafr.html.

Biologists generally use the term "diversity" to refer to speciation within a given body type or phylum. To cite just some examples that are familiar to nonspecialists, the first fish fossils are found in the Ordovician, amphibian fossils in the Devonian, reptile fossils in the Permian, mammal fossils in the Triassic. Furthermore, there is extensive fossil evidence pertaining to how species within these taxa have either diversified or gone extinct. Although hypotheses about detailed direct lineages are always subject to revision, the fossil record clearly shows that modern fish, amphibians, mammals and birds are descended from earlier life. Furthermore, fossil evidence continues to accumulate for the transition periods between such interesting cases as fish and amphibians, land animals and whales, and therapod dinosaurs and birds.

Similarly, the fossil record for plants provides extensive evidence of their development. The first vascular plant fossils are in the Silurian and the vascular plant fossil record becomes increasingly complex throughout the Devonian. By late in that period ferns enter the fossil record followed shortly thereafter by spore producing trees. The first seed producing plants are also found in the late Devonian and their fossil record diversifies throughout the Carboniferous. Conifer fossils are first found in the Triassic and the earliest fossils of flowering plants are not found until the early Cretaceous. A more detailed discussion of the history of plant life can be found in any textbook on evolution. The historical correlation between the development of insects and plants is also particularly well documented.

Furthermore, the fossil record provides other indicators of descent beyond measures of diversity and disparity of body types. For example, as James Valentine and his colleagues have discovered, the number of cell types increases steadily with 
time at an average rate of one new cell type per three million years (Valentine et al. 1994).

What general conclusion can be drawn from the fossil evidence? Clearly according to some measures the tempo of recorded change has varied significantly. Some species and other higher level taxa are very long lived while others are not. Nevertheless, the fossil evidence looks like an incomplete record of historical development. Consequently, for the overwhelming majority of scientists, the fossil record lends strong inductive support for common descent.

\subsection{THE MOLECULAR EVIDENCE}

Data from molecular biology obviously was not one of the lines of evidence that Darwin could marshal for support of his claim of common descent, but it is one that now has become very significant. We will consider several of the various types of evidence derived from the study of biological molecules that are consistent with common descent: (a) protein sequences; (b) ribosomal RNA (rRNA) sequences; and (c) retroviral sequences in DNA.

The last half of the twentieth century saw the discovery of the double-helical structure of DNA, which contains the genetic information coding for messenger RNA (mRNA), which in turn dictates, with the aid of ribosomes, the sequence of amino acids in the myriads of proteins that catalyze the complex web of cellular metabolism. Those stretches of DNA and RNA that code for proteins (called structural genes) employ a genetic code in which 61 base-pair triplets code for the 20 amino acids found in proteins, as well as three codons used for control functions. This code is virtually universal in all life on earth. DNA also codes for the specific sequences of RNA in ribosomal RNA, which, with associated proteins comprise the ribosomes. Information about the function and lineage of each type of molecule, DNA, rRNA, and proteins can be obtained by determining the linear sequence of the monomers making up these biological polymers from various contemporary organisms.

\subsubsection{Protein Sequences}

The linear sequences of amino acids of thousands of proteins have been established as well as many hundreds of the three-dimensional structures by which they fold up into biologically active forms. In the last decade the technology has rapidly developed that allows the sequencing of entire genomes worth of DNA and provides a vast wealth of molecular information about life. Either by determining the amino acid sequences of proteins directly or by determining the nucleotide sequences of DNA in genomes and translating, with the aid of our understanding of the genetic code, into the amino acid sequence of the protein, it is possible to obtain information about both the biologically functional protein molecule and the gene that coded for it. Amino acid sequences of particular proteins, such as the small, mitochondrial protein involved in cellular respiration, cytochrome $c$, or the 
oxygen binding proteins myoglobin and hemoglobin, compared with their threedimensional structures from various species, showed that although the amino acid sequences might show differences between species, the folded protein structure was preserved along with its biological function.

For example, cytochrome $c$ from humans is identical with that from chimpanzees, but only $91.3 \%$ similar to that of a mouse. A fish, such as a carp, is identical to human in only $78.6 \%$ of its sequence. Going further afield, corn cytochrome $c$ shows only $66.7 \%$ identity with the human protein and a fungus, such as Neurospora $63.7 \%$. The pattern shows that organisms that are closely related have identical or very similar sequences of a particular protein, and that as they become more distantly related the sequences show a smaller number of identical amino acids in the sequences (Fitch \& Margoliash 1969; Margoliash et al. 1969; Dayhoff 1972). This is the molecular correlate of the morphological comparisons that taxonomic biologists have made for many years, both of which can be likened to comparing characteristics of relatives of various degrees of relatedness at a family reunion. It turns out that all organisms that utilize oxygen have cytochrome c proteins whose sequences reflect a pattern of divergence from a common ancestral gene. Richard Dickerson, by comparing both sequences and three-dimensional structures of various cytochrome $c$-like molecules from bacteria, including bacteria that are anaerobic, has provided evidence that the particular folding pattern of cytochrome $c$ has arisen from even an older ancestral gene (Dickerson 1971; Dickerson 1980; Dickerson et al. 1976).

These studies led to a burgeoning field of molecular evolution in which proteins were used to construct patterns of relationships as measured by the numbers of mutations (the mutational distance) among proteins derived from a number of different species. Techniques were developed (and continue to be refined) to use such data to construct phylogenetic trees relating such organisms. Today such trees are more likely to be constructed from DNA sequence data since that has become more readily obtainable.

The observation of the stability of the folded structure of proteins in spite of considerable (though not unrestricted) variation in amino acid sequence, along with parallel developments in population genetics, lead to the development of the concept of neutral molecular mutations (Kimura 1968, 1983; King \& Jukes 1969). Emile Zuckerkandl and Linus Pauling suggested that such molecules in effect could act as molecular clocks with neutral mutations occurring roughly correlated with geological time (Zuckerkandl \& Pauling 1965; Kimura 1987; Zuckerkandl 1987). Richard Dickerson further pointed out that the rate of the clock for any given molecule was dependent upon how many molecular constraints acted on the molecule as it functioned in vivo (Dickerson 1971). Thus some highly constrained molecules, such as histones, might accept mutations rarely in hundreds of millions of years, and others, such as the fibrinopeptides studied by Russell Doolittle, accepted mutations in times of less than a million years (Doolittle \& Blomback 1964; Doolittle 1987). Combining data from a number of different pro- 
teins provided a clock that covered a wide span of geological time (Langly \& Fitch 1974). Alan Wilson, among others, further developed the notion of a molecular clock and showed that indeed the genealogies of genes track neutral or near neutral changes over time and are not directly correlated to organisms' morphological changes; the latter instead appear to reflect changes in the genes involved in the regulation of gene expression during development (King \& Wilson 1975). At the molecular level, albumins and hemoglobins of different species of frogs or toads show as much molecular variation as among mammals, even though mammals have shown significant changes over the last 65 million years compared with the unchanging skeletons of frogs and toads compared with fossils (references cited in King and Wilson 1975). In time it was learned that molecular clocks do not always 'beat' at a constant rate and that there are variations along certain lineages $(\mathrm{Li}$ 1997; Page \& Holmes 1998). Just as refinements in calculating phylogenetic trees continue to be devised, so too with the calculations of molecular clocks. What is remarkable is that at an overall level the pattern of molecular phylogeny and the timing of divergences is supportive of the claim of common descent. There have been many controversies as molecular approaches challenged more traditional ones of paleontology and taxonomy. Although we are still in the process of learning how to assimilate the various strands of data, such controversies do not cast in doubt the overall pattern of common descent (Lewin 1999).

\subsubsection{Ribosomal RNA Sequences}

Ribosomal RNA sequences have been widely used because of the initial technical ease of sequencing small RNA molecules compared to that of proteins or DNA. Also, rRNA accepts changes at a slower rate than most proteins because of the central role they play in protein biosynthesis and the large number of molecular interactions they have within a functioning ribosome. The rRNA involves one to one changes with the DNA that codes for it (termed rDNA) in contrast to the triplet codons used for amino acids in proteins; interpreting changes in rRNA and rDNA thus avoids issues about the redundancy of the genetic code. For example, rRNA sequences have helped clarify the phylogenetic and taxonomic relationships of major metazoan alliances (Aguinaldo \& Lake 1998; Valentine \& Hamilton 1998). Ribosomal RNA is of two kinds, that found in the small subunit of ribosomes, or SSU rRNA, and that found in the large subunits of ribosomes, or LSU rRNA. Until recently SSU rRNA has been primarily used even though some technical limitations exist for detailed interpretation. However, recent incorporation of LSU rRNA with SSU rRNA sequence data has been shown to provide substantial improvement in the reliability of the phylogenetic trees constructed (Medina et al. 2001). Although there are controversies about details, and there are on-going refinements of methodology and improvements in the types of data sets employed, the picture from ribosomal sequence studies remains consistent with the claim of common descent, especially for metazoan evolution (Avise 1994). Issues arising from the study of rRNA sequences of bacteria and archibacteria will be addressed below. 


\subsubsection{Retroviral Sequences}

Most students show a keen interest in the results of the human genome project, which can only be fully understood by comparison with genomes of other species. A surprise that has come from looking at such data is that a considerable portion of the DNA is derived from what had been RNA virus infections (Li 1997; Page $\&$ Holmes 1998). The most common gene in the human genome (thousands of copies) is for reverse transcriptase (a catalyst for the transcription of RNA into DNA), a protein that serves no function in the human body, so far as we know (Venter et al. 2001; International Human Genome Sequencing Consortium 2001; Li et al. 2001). However, reverse transcriptase is essential for the action of RNA viruses, including the AIDS virus. The reverse transcriptase genes are part of the genome of RNA viruses that has been transcribed into DNA and inserted in the genome. Although there are several thousand nearly complete viral genomes in our DNA (about 1.3\%), most are inert or are missing a key gene. Although these genes are not expressed and are not functional, they are replicated and transmitted generation to generation, and over time these retrogenes mutate and diversify. Looking at patterns of retroviral sequences can distinguish animals that share a common ancestor, and can provide an estimate of when the divergence occurred using the molecular clock.

For example, the retroviruses found in the DNA of whales hints at their past descent. Whales, hippos, deer and giraffes have three shared retroviruses, each in the same location in the DNA. This is the sort of data that shows that deer are more related to whales than to pigs. Comparison of ten additional retroviruses in the genomes of the species studied shows that whales are more closely related to hippopotami and more distantly related to deer, pigs, and camels. Based upon estimates using the molecular clock, the ancestor common to both whales and hippos should have existed about 55 million years ago, just before Himalayacetus, the earliest known whale fossil (Nikaido et al. 1999). Application of similar studies to primates has also been reported (Johnson \& Coffin 1999). Although such data does not directly address the issue of 'universal common descent', it is very useful for examining the patterns of descent of more limited lineages. In the next few years the study of whole genomes (genomics) and how the information is organized (bioinformatics) should provide even more precise information with regard to the factual claim of common descent.

\section{Response to Wells' Paleontological Objections to Common Descent}

Wells finds what he considers to be problematic paleontological evidence by discussing some aspects of the Cambrian fossil record, the period falling roughly between 545 and 490 million years ago. He argues that the rapid increase in animal disparity during the Cambrian cannot be denied by citing either an incomplete fossil record or the fact that most pre-Cambrian life did not fossilize well. But according to Wells, 'the fact that phyla and classes appeared right at the start' poses 
an insurmountable 'challenge to Darwin's theory' (Wells 2000, p. 41). He further asserts that 'one could even say that the Cambrian explosion stands Darwin's tree of life on its head' (Wells 2000, p. 42). The following passage is a typical expression of what Wells considers to be problematic about Cambrian fossils.

Darwin's theory claims that phylum- and class-level differences emerge only after a long history of divergence from lower categories such as species, genera, families and orders. Yet the Cambrian explosion is inconsistent with this picture. (Wells 2000, p. 41)

Before addressing Wells' charges, the caveat should be noted that neither Wells himself nor either of the present authors is a paleontologist with specialized knowledge of the Cambrian fossil record. Nevertheless, our study of the relevant scientific literature shows that Wells has not advanced a convincing paleontological argument against the thesis of common descent. Controversies pertaining to the fossil record clearly abound, but they do not place the thesis of common descent in a controversial status.

Our response is in two stages. We argue first that Wells inappropriately relies upon the ambiguity of the phrase 'Darwin's theory' to misleadingly divert attention from the well-established thesis of common descent to the on-going efforts to establish a convincing theoretical explanation for the complicated lineages that comprise common descent. Secondly, we argue that Wells inappropriately discusses only the so-called 'Cambrian explosion' and ignores the rest of the fossil record. Furthermore, in his discussion of the Cambrian period, Wells severely distorts the content and import of the relevant scientific literature.

\subsection{FACT AND THEORY REVISITED}

First of all, as we have already argued in detail, there is a fundamental epistemological difference between the factual assertion of common descent and theoretical efforts to stipulate relevant causal mechanisms. Wells repeatedly uses language that blurs this distinction. He refers over and over again to how 'Darwin's theory' is placed in jeopardy by the fossil evidence. But this chapter of his book supposedly confronts the thesis of common descent and textbook representations of that thesis. Instead, Wells' frequent allusions to 'Darwin's theory' (Wells 2000, p. 38) generate an atmosphere of ambiguity so thick that many lay readers will not realize that he has diverted their attention from the well established thesis of common ancestry to the much more contentious disputes about the mechanisms that have caused this ancestral phenomenon. Obfuscation is a useful rhetorical tool, but it is an inappropriate strategy in a scientific context. Wells' misleading usage is well illustrated in the following passage.

Clearly, the Cambrian fossil record explosion is not what one would expect from Darwin's theory. ... Since higher levels of the biological hierarchy appear first, one could even say that the Cambrian explosion stands Darwin's tree of life on its head. If any botanical analogy were appropriate, it would be a lawn rather than a tree. (Wells 2000, p. 42) 
It may be that Darwin, and perhaps some neo-Darwinists, not only expected natural selection to gradually develop higher level taxa from variations within a species but also expected the fossil record to uniformly reflect this process. But this theoretical expectation should be uncoupled from the question of whether the fossil record provides evidence in support of common descent. Wells claims that because 'higher levels of the biological hierarchy appear first' in the fossil record, this means that "the fossil record from the Cambrian on is inappropriately "top-down" rather than "bottom-up"'. But Wells overlooks the fact that this phenomenon is the result of imposing a modern taxonomic classification scheme upon a historical record. Geologist Keith Miller has succinctly expressed this point as follows.

When a hierarchical classification is applied retrospectively to a diversifying evolutionary tree, a "topdown" pattern will of necessity result. Consider, for example, species belonging to a single evolving lineage given genus-level status. This genus is then grouped with other closely related lineages into a family. The common ancestors of these genera are by definition included within that family. Those ancestors must logically be older than any of the other species within the family. Thus the family level taxon would appear in the fossil record before most of the genera and species included within it. The "top-down" pattern of taxa appearance is therefore entirely consistent with a branching tree of life. (Miller 1997, p. 265)

We will return to the issue of the appropriateness of the 'tree' analogy in a later section. We should note in passing that Wells also trades upon the ironic fact that as more and more fossil evidence accumulates, the precise lineages that constitute the history of life are revealed to be more and more complicated. But as many of us know from personal experience, small families make for relatively easy genealogies and large families are more difficult to analyze. Since the full size of the tree of life is unknown, it is to be expected that new data will reveal new complications.

\subsection{THE CAMBRIAN EXPLOSION}

Wells tries to make his assertions about the fossil record look plausible through an extremely selective discussion. Rather than address the full complexity of the fossil record, he directs his readers exclusively to the Cambrian explosion of multicellular animal life. Plants are not mentioned at all and animal life before and after the Cambrian period receives no serious attention. Obviously our knowledge of the history of life during the Cambrian is incomplete, but why should this overshadow all that we do know?

Furthermore, how accurately does Wells present what is known about the Cambrian explosion? He claims that phylum level differences among multicellular animals appear 'right at the start'. But how accurate is it to refer to Cambrian fossils dating three billion years after that of the earliest documented fossils of life as appearing 'right at the start'? In stark contrast to the complex nature of the preCambrian fossil record, Wells uses language couched in a manner that may well mislead lay readers into thinking that the Cambrian fossils he discusses are the earliest known evidences of life. This of course is not the case and it is deceptive 
of Wells to use language that might be interpreted by non-specialists to conclude otherwise.

Furthermore, in the course of his inappropriate over-emphasis on animal phyla with skeletons, Wells misrepresents the scientific literature concerning both preCambrian life and the fossil evidence for subsequent emergence of phyla after the Cambrian. For example, Wells writes as follows:

British paleontologist Simon Conway Morris believes that at least some of the Ediacaran fossils were animals, but maintains that most of the many species appearing in the Cambrian did not have ancestors in Ediacara. "Apart from the few Ediacaran survivors", wrote Conway Morris in 1998, "there seems to be a sharp demarcation between the strange world of Ediacaran life and the relatively familiar Cambrian fossils". (Wells 2000, p. 38)

The quoted passage from Conway Morris turns out to be from page 30 of his 1998 publication The Crucible of Creation. Even a cursory glance at that page reveals that Wells has distorted Conway Morris's position. Conway Morris's point was that the Cambrian period is where hard skeletal parts first appear in the fossil record. He wrote nothing that would imply that he thought Cambrian animals were not descendents of Ediacarans. Indeed, on the following two pages he writes:

The term "explosion" should not be taken too literally, but in terms of evolution it is still very dramatic. What it means is the rapid diversification of animal life. "Rapid" in this case means a few million years, rather than the tens or even hundreds of millions of years that are more typical when we consider evolution in the fossil record. (Conway Morris 1998, pp. 31-32)

Wells notes that the microscopic soft-bodied nature of pre-Cambrian life has sometimes been cited as a reason for the relatively sparse pre-Cambrian fossil record. He dismisses this explanation by pointing out that many fossils of soft-bodied preCambrian life have been discovered. This glib observation hardly does justice to the many factors that bear upon the preservation of soft-bodied fossils. Wells quotes Conway Morris as writing that the Burgess Shale Cambrian fossils are also softbodied. But Conway Morris's point was to note that this is one of the reasons that the Burgess Shale fossils are so special (Conway Morris 1998, p. 2). Wells also quotes some comments by renowned paleontologist J. William Schopf in which he points out that microscopic soft-bodied life has left extensive evidence in the preCambrian fossil record and this is contrary to earlier speculations that these fossils would not be found due to their small size and soft consistency. But Schopf certainly did not want to imply that the pre-Cambrian fossil record is well understood. In the same article from which Wells quotes, Schopf wrote as follows.

Because of the enormous span of Precambrian time - and despite the notable progress of recent decades - early biotic history and the interaction of the evolving biota with the developing early environment are as yet very incompletely documented. (Schopf 1994, p. 377)

One of the general conclusions Schopf draws from what is presently known about the full scope of the fossil record is that life has evolved through two fairly distinct stages (Schopf 1999, pp. 271-272). Prior to the Cambrian, microscopic life consisted of very long-lived generalists. A relatively small number of species 
typically survived for almost inconceivably vast periods of time and flourished in very extensive environments. Thereafter, life became far more diverse and more ecologically specialized; relatively sudden extinction events became the rule and they often were followed by rapid diversification of other species. Although the Cambrian period straddles the transition between these two phases and thus is an appropriate object of our scrutiny and fascination, it is misleading for Wells to imply that the Cambrian fossil record constitutes evidence against the thesis of common descent.

In this connection, it is worth taking note of the distinction that paleontologists draw between the two concepts of diversity and disparity. Simon Conway Morris has recently drawn attention to this interesting distinction (Conway Morris 1998, pp. 206-218). Diversity usually refers to how many species exist at a given point in time. Conway Morris notes that the fossil record indicates that diversity generally increases through time, even taking into consideration the greater probability that relatively recent species are more likely to be detected in the fossil record than older species. On the other hand, Conway Morris characterizes disparity as the 'range of different types or designs', a notion often referred to as body plans (Conway Morris 1998, p. 206). Can this concept be quantified and measured? It certainly is not obvious that there is one straightforward manner in which to do so. Conway Morris's reading of the fossil record leads him to conclude that disparity is far more difficult to generalize about than diversity. Simply counting alleged phyla is too simplistic since the assignment of Cambrian and pre-Cambrian fossils to particular phyla is always problematic. As we have already pointed out, phylum classification based upon predominately modern fossil data is not particularly trustworthy.

Conway Morris cites Gould's popular book Wonderful Life (Gould 1989) as contributing to the widespread perception that Burgess Shale fossils are convincing evidence for an 'inverted cone of life'. Conway Morris argues that Gould's interpretation of the Burgess shale is not convincing. Just as Gould and Eldredge proposed a step-wise model for speciation, Conway Morris proposes an analogous model for the history of disparity. Writing in response to the view Gould advanced in Wonderful Life, Conway Morris proposes that other possibilities are at least equally well supported by the evidence.

First, it is worth realizing that that the concept of 'inverted' or 'upright' cones of disparity are not the only possibilities. For example, it is conceivable that the disparity in modern oceans is much the same as it was in the Cambrian..... Alternatively, it could be the case that disparity has indeed increased through geological time, but in a step-like manner rather than in a regular fashion. ... In this case one could envision occasional innovations in evolution, the consequences of which ripple through the biosphere and so drive times of rapid change. (Conway Morris 1998, p. 208)

With respect to measures of disparity in the fossil record, Wells' concentration on phyla as the only taxon worthy of discussion thus is extremely problematic. Why should phyla be the only relevant taxonomic concept? Conway Morris has some additional relevant comments. 
What this chapter will try to show is that the strangeness of the problematic Cambrian animals is really a human artifact, a construct of our imagination. This is not to deny that a number of these animals remain very difficult to understand, especially in terms of their phylogenetic relationships. Nevertheless, we can now be confident that ultimately these too will be explained. (Conway Morris 1998, pp. 170-171)

Conway Morris then proceeds to present detailed examples of how cladistic analysis is making classification schemes less and less arbitrary. Furthermore, as we have already pointed out, complexity as measured by James Valentine and his colleagues is another indication that the Cambrian, for all its unique aspects, is not as anomalous as Wells makes it out to be (Valentine et al. 1994). Specific relationships and lineages may be controversial, but not the fact that the history of life has proceeded through a long process of descent with modification.

\section{Response to Wells' Objections to Common Descent based on Molecular Data}

After trying to use fossil evidence from the Cambrian explosion as an argument against common descent, Wells characterizes the plethora of molecular studies of protein, rRNA, DNA, and whole genome sequences of metazoans as an attempt to rescue this factual claim. To the casual reader Wells' argument might seem to be amply documented by the primary literature. However, Wells does not mention the fact that most of the papers he cites come from research groups that have been studying evolution at the molecular level for a considerable time and in a much broader context than simply trying to patch up the 'problems' he claims that the Cambrian Explosion presents. He argues that differences in the interpretation of the data between the various research groups renders all their claims suspect. Further he argues that the molecular phylogeny approach is unreliable in any event and produces non-biological groupings of animals. Then he concludes with arguments that the genome studies of prokaryotes and the Archaea have uprooted the 'tree of life', thereby falsifying common descent. We will examine each of Wells' claims in turn.

\subsection{MOLECULAR PHYLOGENIES}

Wells notes that different research groups have reported a range of dates $(1.2,1.0$, 0.67 , and 0.57 billion years ago) for the divergence of the animal phyla. Implicit in Wells' critique is the expectation that interpretation of molecular data should be unambiguous, routine, and simple, with direct and immediate correlations to the fossil and morphological evidence. However, the science that is actually being practiced deals with both legitimate methodological issues and the realities of biological complexity. Taken at face value the molecular divergence estimates are all earlier than 543 million years ago when the Cambrian explosion appears to have started. 
Reading the literature Wells cited indicates that there are differences in judgment by the experts as to how best to treat and interpret the molecular sequence data. Such disputes are commonplace in any developing scientific discipline. Indeed, a biology instructor should convey to students that science is not a body of fixed knowledge, but a process by which we learn more about nature. Because new types of knowledge are sought using new methods, a vibrant debate is to be expected. Expanding the data base by inclusion of more sequences and using increasingly sophisticated statistical treatments provides greater confidence that the lineages of genes that appear in the metazoa predate the time of the Cambrian explosion by a minimum of 110 million years and probably more (Bromham et al. 1998).

Reading some literature not cited by Wells provides additional support for dating the divergence of the lineages of genes found in present-day animal phyla prior to 530 million years ago. For example, the work of S. Blair Hedges and colleagues, based on the largest number of gene sequences to date, gives statistically significant results indicating that the divergence of animal genes began about 400 million years before the Cambrian explosion (Wang et al. 1999). They emphasize that they are following the lineages of the genes of metazoans, which are not necessarily directly coupled with the lineage of the fossil record. It has been known for some years that there is not a strict coupling of changes in structural genes and changes in the morphology of organisms; the latter is the result of changes in developmental regulatory genes and their arrangement in the genome (Wilson et al. 1977; Gilbert 1997; Shubin et al. 1997; Gehring 1998; Carroll et al. 2001). James Valentine and colleagues have recently argued that what matters are the changes that occurred in the Hox genes (some of the genes involved in development) about the time of the Cambrian explosion, even though those genes appear to have originated earlier than the diversification of metazoan body plans (Valentine et al. 1999). In time a consensus may well emerge in the interpretation of the molecular data along these lines. The current controversy noted by Wells is not damaging to the claim of common descent; indeed, the bringing together of fossil, molecular genetic data, and an increasing understanding of the mechanisms of development and the relationship of these to evolutionary change, should deepen our understanding of this important transformation, the emergence of metazoans, in life's history. As our understanding of this emergence deepens, so too does the compelling evidence of common descent (Schwartz 1999; Conway Morris 2000; Baldauf et al. 2000).

\subsection{MOLECULAR CLOCKS}

Wells questions the use of the 'molecular clock' as part of his criticism of the estimates of the divergence times. The clock was first proposed by Pauling and given a theoretical basis by Kimura and Dickerson, as mentioned above. But, as Hedges and colleagues point out, whether or not it is adequately explained by theory, it appears as an empirical correlation (Wang et al. 1999). Of course 
the molecular clock turns out to be somewhat variable, especially along certain lineages. Indeed, it is the apparent 'clock-like' rate of neutral or nearly neutral mutations as a function of time that allows molecular sequence data to provide phylogenies that on average compare well with those more traditionally produced. Further, because of frequent gene duplication, there is the danger of comparing paralogous rather than orthologous genes ${ }^{1}$ when using the clock or when constructing phylogenies based upon molecular data. Also, many practitioners in the field have warned of the possibilities of convergent evolution at the molecular level that can mislead attempts to construct phylogenetic trees. Finally, it is necessary to make the assumption of minimum mutational distance in order to reduce the astronomical number of possible phylogenetic trees relating the data to a manageable number. However, there is no guarantee that only the minimum number of mutations in fact occurred during descent over time; some slippage thus can occur when relating gene genealogies to those of fossils. Some research groups attempt to make statistical corrections for such mutational walk. These are real difficulties that need to be carefully considered when using molecular approaches, and they can be shared with and explored by students. Thus there can be differences in interpretation depending upon which sequences are selected for comparison, how long they are, how many different genes are used, how the data are analyzed statistically, and how possible variations in the molecular clock are modeled. Much of the professional literature addresses how to develop criteria to objectively evaluate which sequences should be used or excluded in calculating the most probable phylogeny. Dealing with smaller sections of animal phylogeny has fewer problems than when dealing with large-scale phylogenies. This is due in part to the apparent widespread horizontal gene transfer within and between prokaryotes and Archaea (Woese 1998, 2002; Doolittle 1999, 2000) which occurs to a much lesser extent, if at all, among higher animals (Andersson et al. 2001; Salzberg et al. 2001). Also, in animal lineages there are the additional resources of many retroviral sequences that can help resolve phylogenetic ambiguities, as mentioned above.

Although Wells says nothing about the appearance of plants, from his silence one might infer that they also appeared during the Cambrian explosion. But fossil evidence of plants and fungi first show up significantly later, about 480 to 460 million years ago. However, recent analysis of 119 orthologous fungi protein sequences, with comparisons to various plant sequence data, suggests that green algae and fungi lineages go back a billion years and that the divergence of the genes coding for these proteins in plants diverged from fungi about 700 million years ago (Heckman et al. 2001). As with the appearance of animal phyla, the genes have histories that go deeper than the fossil data. The reasons for the disparity of the fossil record and the molecular information may be similar in both cases, with the appearance of complex fossil forms reflecting changes in developmental genes of already existing lineages. Such data strengthen rather than weaken the factual claim of common descent. 
Wells goes on to give examples of what he considers to be biological 'bloopers' provided by several selected molecular phylogenies. Wells cites as an anomaly the report by Graur's research group that rabbits are closer to primates than rodents (Graur et al. 1996). After we have our chuckle however, reading the paper shows that the placing of rabbits taxonomically and phylogenetically has been a vexing problem for biologists over the past two hundred years. Graur and colleagues in fact make a compelling argument for the placement that they discovered, based upon an analysis in which they compared the sequences of 88 different proteins from a large number of species in sixteen different major taxa.

Another alleged anomaly Wells mentions is the placement of sea urchins among the chordates by Halanych (1998). However, the point of the article was the problems with using only 18SrRNA sequences; there was ample discussion of the various possible sources of the problems with specific caveats about the adequacy of the data set and methods of phylogenetic tree construction. Halanych anticipates better trees when an order of magnitude increase in the amount of genes compared is achieved, an expectation that is beginning to be realized (Wang et al. 1999).

Finally, Wells draws upon our barnyard intuitions to be amused that another study placed cows closer to whales than horses in a study of the genes coding for a dozen proteins in mitochondrial DNA (Cao et al. 1998). However, cows (family Bovidae) and hippopotami (family Hippopotomidae), which have been shown by retroviral sequence analysis to be phylogenetically close to whales (Johnson \& Coffin 1999), are in the order Artiodactyla. The whales are placed in their own separate order by taxonomists. Horses are in the family Equidae in the order Perissodactyla. So the placement by Cao and his colleagues is hardly the problem that it appeared to be to Wells. Indeed, in the article Cao and his co-authors did not feel the need to comment on the relative position of horses, cows and whales since they were in fact not problematic. They were concerned with addressing technical problems in the construction of the phylogenetic trees, but these Wells passed over in silence. Wells is correct that there are difficulties and disputes in the interpretation of the molecular evidence, but the problems are not the ones that he chooses to highlight. While selective quotation, out of context, and ignoring the main arguments of a paper in the primary literature may be rhetorically successful with some audiences, such a ploy is not in the spirit of scientific or scholarly discourse and debate; nor does Wells meet the requirement of trustworthy popularizers of science that the science not be distorted in the retelling.

\subsection{THE TREE OF LIFE}

Wells takes the work of Carl Woese and of W. Ford Doolittle, as the coup de grace that 'uproots the tree of life'. Admittedly Doolittle did use such a rhetorical flourish in the title of his recent Scientific American article, but Wells does not fairly report on the arguments actually made by Woese (1998) and Doolittle (1999, 2000). Both are dealing with the fact that as genomic data becomes available there is evidence 
of significant horizontal gene transfer within various bacterial taxa (prokaryotes) and within the Archaea taxa, as well as between both kingdoms. Doolittle suggests that a better metaphor for the phylogeny relating all life would be a 'thicket' rather than a tree, reflecting concerns of Woese that it may not be possible to follow at this great remove the true line of common descent or that there may be indeed multiple origins, or better emergences, of living systems. Hypotheses of the emergence of life that employ some of the resources of complex systems dynamics have considered that life would have emerged as an ensemble of protocells, rather than a given original, individual cell (Kauffman 1993; Weber 1998). In Kauffman's computer simulations, the 'catalytic closure' that would produce a self-sustaining proto-metabolism would arise in such an ensemble of osmotically distinct protocells no one of which has all the chemical reactions or even necessarily the same type of catalysts (polypeptides, catalytic RNA, etc). Although students have a natural interest in such questions, only those with a sufficiently strong chemistry background are likely to profit from more than being presented with an impression of the present status of such work.

From totally different considerations Woese envisions a similar process. Even as the 'evolutionary temperature" 2 cooled down in early cellular life and a more or less common metabolism arose, there would have been a fair amount of residual flow of genetic information between cells and later species reflecting diverging lineages of cells (Woese 1998, 2002). Ultimately, from this 'pregenate ancestral core' emerges the three domains (Eubacteria, Archaea, and Eukaryota). This initial web of lineages might be likened to a complex root system of a thicket or multitrunk tree.

Do these ideas pose a threat to the fact of common descent? Certainly Darwin allowed that there might have been more than one first common ancestor. 'There is grandeur in this view of life, with its several powers, having been originally breathed into a few forms or into one; ...' (Darwin 1859, p. 490). Further, Darwin could only consider the post Cambrian radiation of metazoa. It is interesting to note that this is the side branch in Wells' Fig 3-8, which looks remarkable like the more conventional 'tree of life' (Wells 2000, p. 53). Wells heaps scorn on the notion that Woese sees the 'root' of the tree as complex and the 'common ancestor' as a process. This says something about what Wells thinks the expectations are of his readers. In the sciences of complexity such a 'process' might indeed be the vehicle by which life emerges. We need not expect that there is a particular bacterial cell that is the ancestor of us all. Rather, there are lineages that do radiate from some ancestral forms for each kingdom; blue whales and cows evolved from a series of common ancestors going back to a metazoan ancestor, which in turn emerged from unicellular eukaryotes. Woese and Doolittle do not doubt the reality of common descent, despite the imputations of Wells, but rather are dealing with the implications of the molecular data, which gives a perspective that presents an increasingly complex network. This does not put the claim of common descent at jeopardy, but rather makes the study of evolutionary biology more vital and 
interesting to those actually studying such phenomena. Even though the picture of the relationships between genes of Archaea and Bacteria is complicated because of horizontal gene transfer, this does not mean that there might not be some evidence of common ancestry of these two taxonomic groupings. Indeed, a recent study of the patterns of certain motifs in the sequences of proteins involved in the regulation of the transcription of DNA into RNA (repressors) in both Bacteria and Archaea shows that many of the repressor molecules share a common origin prior to the divergence of Archaea and Bacteria (Perez-Rueda \& Collado-Vides 2001). The picture may be complicated and the 'tree of life' may look more like a thicket than a pine tree, but the thicket still appears to be one of common descent. This is a point that can be appreciated by students at all levels.

Although the above discussion of the molecular data and the Cambrian explosion present a more complex picture with regard to common descent than that portrayed in high school or introductory college textbooks, it still indicates that there are many practicing biologists, including those quoted, who strongly support the factual claim of common descent. It is fair to report to students that on-going research indicates that the picture is more complex than typical textbook treatment, but it is a major distortion to suggest that scientists are rejecting common descent, or that they are scrambling to shore up increasingly rickety evidence. There are a few individuals with scientific training who have philosophical, and in some cases scientific, objections to the claim of common descent; but of those actually working in the relevant disciplines there are virtually none who reject common descent.

\section{Is the 'Tree of Life' a Misleading Icon?}

Contrary to Wells, common descent is not 'the foundation of Darwin's theory' (Wells 2000, p. 31). It is a complex phenomenon for which Darwin and subsequent theorists have tried to develop explanations. We have argued that paleontological and molecular evidence alone amply justify the assertion of common descent. There are good reasons that the scientific community has come to consensus on this issue and Jonathan Wells' arguments in Icons of Evolution do not justify pedagogical presentation of that consensus as controversial.

What does this conclusion imply for the so-called 'icon' of 'the tree of life'? First of all, any specific tree depicted in a textbook is necessarily a simplified representation of the well-established fact of common descent. Any particular diagram is simplified in the sense that it cannot possibly capture all that is known about the complex relationships among the various forms of life. Nor is any modern textbook diagram intended to do so. As every competent teacher knows, no diagram speaks for itself; every diagram must be interpreted so as to make a particular point. In particular, any biological 'tree of life' can be presented in a misleading manner to imply that more is known than is actually the case. But good teachers use simplified diagrams and models appropriately while poor teachers do not. As scientists learn more and more about the history of life, any number of metaphors 
and models should be marshaled to convey better and better approximate representations to what is known. Good teachers realize that every such simplification has both strengths and weaknesses. To cite an obvious example from chemistry and physics, the Bohr model of the atom still provides useful insight into the structure of the atom even though it is well-known to fall far short of the more accurate description provided by quantum mechanics. Is the Bohr model a misleading 'icon' that should be stricken from physics and chemistry textbooks? Of course not, but the limitations of the model need to be pointed out to students at the appropriate stage in their development. Similar examples can be found in hydrology where idealized models are used in the analysis of ground water flow.

Darwin actually demonstrated remarkable foresight in his initial choice of a 'tree' as a metaphor for the history of life. As the fossil record clearly shows, trees themselves have evolved through time in a fascinating and elaborate manner. Similarly, idealized and incomplete 'trees of life' have also evolved in response to the steady influx of paleontological and molecular data. Just as there is no single illustration that completely captures the evolving botanical complexity of trees, so too there is no single 'tree of life' that should be expected to be a conclusive representation of common descent. As we have noted, Simon Conway Morris emphasizes that there is indeed controversy about the very large-scale structure of the tree among paleontologists (Conway Morris 1998, pp. 206-208). Similarly, the node of all nodes, the starting point for all life, turns out to be too complex to be represented as the tip of a tree's central taproot. Darwin wisely did not try to include it in his own famous tree. As we have discussed in some detail, Carl Woese has been at the forefront of recent efforts to understand the web of relationships that developed during the first three billion years of life. His 1990 proposal to classify early life in the three categories of Bacteria, Archaea and Eucaryotes was motivated in part by his research into the rampant horizontal gene transfer that took place during life's early stages. More controversially, Woese argues that all three domains may be as old as 3.5 billion years. Whether Woese turns out to be correct on this point or not, the early prevalence of horizontal gene transfer means that genes initially were more likely to be transferred than to be inherited. In a recent semi-popular book, Carl Zimmer comments on the impact of this research on the metaphor of a 'tree of life'.

On the early Earth, Woese claims, there was no genealogy. Life had not yet separated into distinct lineages, and thus no single species lies at the base of the tree of life. Our common ancestor was every microbe that lived on the early Earth; a fluid matrix of genes that covered the planet.... If Woese turns out to be right, the tree of life will have to be redrawn yet again. Instead of a bush, it will have to look more like a mangrove, with a tangle of roots at its base representing the mingling of early genes. Gradually the three trunks emerge, but their branches entwine with one another many times. (Zimmer 2001, p. 109)

Mangrove trees thrive in shallow saltwater and have elaborate root mangles that extend well above the water surface; some species are even referred to as 'walking trees' because of their unusual appearance. The extensively branching roots are 
used both to provide support and to absorb oxygen. The relationship between the trunks and the root system is far more complex than in more commonly known trees such as pines and oaks. Zimmer thus proposes the mangrove tree as an interesting image for the tree of life, one that to some extent reflects recent research into life's early stages. As always, the image has limitations and these need to be recognized as well. None of this discussion supports any doubt that all forms of life are related to each other, however distantly. Pedagogically, reference to a 'tree' of life is still pertinent insofar as it calls attention to family relationships in a manner that is familiar to most students.

There is another sense in which tree of life diagrams based upon the fossil record might be considered misleading. Real trees are of course open to our inspection, inspection which can reveal how any two branches are related to each other through specific nodes. Nevertheless, as scientists who approach evolutionary relationships from a cladistic or molecular perspective are wont to point out, no matter how much fossil evidence accumulates, we can never be absolutely certain that any particular species detected within the fossil record is the direct ancestor of another (Gee 1999, p. 5). An analogy to human genealogy may make this point more evident. For example, drawing upon our experience with respect to family genealogies, the fact that there are newspaper records of a Johannes Hofmann in 1860 and a Julius Hofmann in 1895 does not allow us to conclude with any rigor that Julius is a direct descendent of Johannes. There may well have been other Hofmanns involved. Darwin's own idealized diagram certainly does include specific nodes for every branching event within the 'tree'. As in the case of an incomplete family tree, none of the nodes in Darwin's tree of life should be interpreted as participants in a direct lineage that can be conclusively substantiated solely by the fossil record. A diagram intended to represent just the fossil evidence would have branches but no nodes. Nevertheless, molecular evidence provides another source of evidence independent from the fossil record. The resulting lineages for genes provide a genetic tree that compliments the history constructed from the fossil record. As the paleontological and molecular data continue to accumulate, the relationships among the branches of life become more and more accurately known. While molecularly inferred nodes may never be correlated with the fossil record with absolute precision, the analogy to a tree continues to be a useful representation of common descent. The realization that the nodes in a schematic tree of life cannot be conclusively correlated with specific fossils can be a disconcerting experience for students who have been too strongly encouraged to think otherwise. But this is the experience students pass through in every scientific field when simplified introductory treatments are replaced with more complex models.

As philosophers are wont to point out, theoretical perspectives do affect scientists' expectations as they carry out empirical research. A heavily branching 'tree of life', is an analogy in keeping with the Darwinian research tradition, and helps distinguish it from some rival evolutionary accounts. Darwin's own version of the 'tree', the icon critiqued by Wells, is actually quite conservative in that it 
has eleven lineages at its 'base'. As such it represents a fairly late stage in what is now known about life's history. Although Darwin did believe that these lineages also were related through common ancestors, he was too cautious to speculate in any detail about the nature of those relationships. So if the use of Darwin's own diagram as an illustration is supposed to be misleading, it isn't because it starts with a single taxon. It still has historical and pedagogical value, as long as its metaphorical nature is made clear to students.

Of course neo-Darwinism is not the only viable scientific explanation for the diversity we see in nature. Lamarckian directional evolution has its modern day supporters as does another research tradition that goes back to Geoffroy St. Hillaire and runs through a number of German developmental biologists to some contemporary developmentalists. The metaphor, or icon if you will, that reflects Lamarckian expectations would be closer to a staircase. The developmentalists would substitute a pine tree that shoots up to man at its pinnacle. Nevertheless, the shape of the tree of life is ultimately an empirical issue and it is being clarified independently from theoretical disputes over the mechanisms of descent. In particular, whether the relationships between pre- and post-Cambrian life are or are not in accord with Darwin's expectations does not invalidate the claim of common descent. ${ }^{3}$ Similarly, evolutionary theory is not a static set of postulates, set either by Darwin or by the founders of the neo-Darwinian synthesis, but a living research tradition that itself evolves as it encounters new types of knowledge about living things.

In conclusion, we should point out that if there is any legitimate controversy at stake here it is certainly not the artificially created dichotomy often drawn between common descent and 'design'. Just as some members of a political party such as the Republicans are also Boston Red Sox baseball fans, some scientists who accept common descent are also materialists who reject all notions of supernatural design as merely apparent. But there is no more causal connection between common descent and materialism than there is between Republican political party status and loyalty to the Red Sox baseball team. It is easy to find proponents of design who accept common descent. We have mentioned Michael Behe and Michael Denton as two well-known examples; Howard Van Till and Denis Lamoureux have been particularly articulate on this subject (Van Till 1999; Lamoureux 1999). Anti-evolutionary writers have attempted to coop the term 'design' so as to make it incompatible with common descent. They have done so by blurring the distinction between design as an intention, on the one hand, and the execution of that intention on the other. Life may well have been 'designed' in the sense that it was divinely intended for a specific purpose. Nevertheless, even if this is the case, the scientific evidence overwhelmingly supports the conclusion that the execution of that intention has been through the process of common descent. Students must be made aware of this fact and should be allowed to draw their own conclusions about whether or not common descent represents the execution of a supernaturally intended design, an issue that is not appropriately decided in a science classroom. 
Notes

1 Orthologous genes are those that have arisen by gene duplication processes that have the same function for their gene products. Changes that arise through mutation of such genes are almost always neutral or near neutral and reflect only the passage of time. Paralogous genes are those that have also arisen by gene duplication but which have gene products that have acquired altered or new biological functions. Changes among paralogous genes reflect both neutral changes and adaptive changes selected for the new function. When comparing a gene from a large number of species there is always the chance that instead of comparing orthologous genes only in some cases paralogous are placed into the data base, thereby producing inaccuracies of both the phylogenetic tree and molecular clock.

2 The term evolutionary temperature is used by Woese as an index of the rate of mutation in ensembles of genetic or protogenetic systems. As the process of transcription and translation improve and the error rates decrease, there is a "cooling" of the pace of mutational change. Woese extends this analogy to DNA hybridization experiments to annealing and "crystallization" phenomena that stabilizes genetic systems and produces greater integration.

3 It is not clear that, other than in the arguments of some 'ultra-Darwinians', that Darwinism is constrained solely to natural selection acting upon effectively infinite variation. Darwin himself was open to bringing in constraints from developmental biology, although in forging the neo-Darwinian synthesis, developmental biologists, such as Conrad Waddington, were marginalized at best. Today there are a number of theoretical and experimental approaches to bringing the insights of developmental biology into evolutionary theory, indeed, some see this as the primary problem of contemporary theoretical biology (for a discussion see Depew \& Weber 1995; Weber \& Depew 2001). In such a view, a channeling along certain types of developmental programs or body plans would be a natural consequence of developmental constraints. Such constraints would have arisen with the appearance of the metazoans. However, within each body plan there has been a process of diversification and radiation after each of the several major extinctions.

\section{References}

Aguinaldo, A.M.A. \& Lake, J.A.: 1998, 'Evolution of the Multicellular Animals', American Zoologist 38, 878-887.

Alters, B.J. \& Nelson, C.E.: 2002, 'Teaching Evolution in Higher Education', Evolution 56(10), 1891-1901.

Anderson, J.O., Doolittle, W.F. \& Nesbe, C.L.: 2001, ‘Are There Bugs in Our Genome?', Science 292, 1848-1850.

Avise, J.C.: 1994, Molecular Markers, Natural History and Evolution, Chapman \& Hall, New York.

Baldauf, S.L., Roger, A.J., Wenk-Siefert, I. \& Doolittle, W.F.: 2000, 'A Kingdom-Level Phylogeny of Eukaryotes Based on Combined Protein Data', Science 290, 972-977.

Behe, M.J.: 1996, Darwin's Black Box. The Biochemical Challenge to Evolution, Simon \& Schuster, New York.

Bogen, J. \& Woodward, J.: 1988, 'Saving the Phenomena', The Philosophical Review 97(3), 303352.

Bromham, L., Rambaut, A., Fortey, R., Cooper, A. \& Penny, D.: 1998, 'Testing the Cambrian Explosion Hypothesis by Using a Molecular Dating Technique', Proceedings of the National Academy of Sciences 95, 12386-12389.

Cao, Y., Janke, A., Waddell, P.J., Westerman, M., Takenaka, O., Murata, S., Okada, N., Paabo, S. \& Hasegawa, M.: 1998, 'Conflict Among Individual Mitochondrial Proteins in Resolving the Phylogeny of Eutherian Orders', Journal of Molecular Evolution 47, 307-322.

Carroll, S.B., Grenier, J.K. \& Weatherbee, S.C.: 2001, From DNA to Diversity: Molecular Genetics and the Evolution of Animal Design, Blackwell Scientific, Malden, MA. 
Conway Morris, S.: 1998, The Crucible of Creation: The Burgess Shale and the Rise of Animals, Oxford University Press, Oxford.

Conway Morris, S.: 2000, 'Evolution: Bringing Molecules into the Fold', Cell 100, 1-11.

Coyne, J.; 2001, 'Creationism by Stealth', Nature 410, 745-746.

Darwin, C.: 1859, On the Origin of Species by Means of Natural Selection, or the Preservation of Favoured Races in the Struggle for Life, John Murray, London.

Dayhoff, M.O.: 1972, Atlas of Protein Sequence and Structure, Vol. 5, National Biomedical Research Foundation, Washington, DC.

Denton, M.J.: 1986, Evolution: A Theory in Crisis, Adler \& Adler, Chevy Chase, MD.

Denton, M.J.: 1999, 'Comments on Special Creationism', in P.E Johnson and D.O. Lamoureux (eds.), Darwinism Defeated? The Johnson-Lamoureux Debate on Biological Origins, Regent College Publishing, Vancouver, pp. 141-154.

Depew, D.J. \& Weber, B.H.: 1995, Darwinism Evolving: Systems Dynamics and the Genealogy of Natural Selection, MIT Press, Cambridge, MA.

Dickerson, R.E.: 1971, 'Sequence and Structure Homologies in Bacterial and Mammalian-type Cytochromes', Journal of Molecular Biology 57, 1-15.

Dickerson, R.E.: 1980, 'The Cytochromes $c$ : An Exercise in Scientific Serendipity', in D.S. Sigman and M.A.B. Bazier (eds.), The Evolution of Protein Structure and Function, Academic Press, New York, pp. 173-202.

Dickerson, R.E., Timkovich, R. \& Almassy, R.J.: 1976, 'The Cytochrome Fold and the Evolution of Bacterial Energy Metabolism', Journal of Molecular Biology 100, 473-491.

Doolittle, R.F.: 1987, 'The Evolution of the Vertebrate Plasma Proteins', Biological Bulletin 172, 269-283.

Doolittle, R.F. \& Blomback, B.: 1964, 'Amino-Acid Sequence Investigations of Fibrinopeptides from Various Mammals: Evolutionary Implications', Nature 202, 147-152.

Doolittle, W.F.: 1999, 'Phylogenetic Classification and the Universal Tree', Science 284, 2124-2128.

Doolittle, W.F.: 2000, 'Uprooting the Tree of Life', Scientific American 282(2), 90-95.

Fitch, W.M. \& Margoliash, E.: 1969, 'The Construction of Phylogenetic Trees', Brookhaven Symposia in Biology 21, 217-242.

Futuyma, D.J.: 1998, Evolutionary Biology, 3rd edn, Sinauer, Sunderland, MA.

Gee, H.: 1999, In Search of Deep Time. Beyond the Fossil Record to a New History of Life, Free Press, New York.

Gehring, W.J.: 1998, Master Control Genes in Development and Evolution: The Homeobox Story, Yale University Press, New Haven.

Gilbert, S.F.: 1997, Developmental Biology, 5th edn, Sinauer, Sunderland, MA.

Gould, S.J.: 1983, 'Evolution as Fact and Theory', in S.J. Gould, Hen's Teeth and Horse's Toes, W. W. Norton, New York, pp. 253-262.

Gould, S.J.: 1989, Wonderful Life. The Burgess Shale and the Nature of History, W.W. Norton, New York.

Graur, D., Duret, L. \& Gouy, M.: 1996, 'Phylogenetic Position of the Order Lagomorpha (Rabbits, Hares and Allies)', Nature 379, 333-335.

Halanych, K.M.: 1998, 'Considerations for Reconstructing Metazoan History: Signal, Resolution, and Hypothesis Testing', American Zoologist 38, 929-941.

Heckman, D.S., Geiser, D.M., Eidell, B.R., Stauffer, R.L., Kardos, N.L. \& Blair Hedges, S.: 2001, 'Molecular Evidence for the Early Colonization of Land by Fungi and Plants', Science 293, $1129-1133$.

Hofmann, J.R.: 1990, 'How The Models of Chemistry Vie', in A. Fine, M. Forbes and L. Wessels (eds.), PSA 1990: Proceedings of the 1990 Biennial Meeting of the Philosophy of Science Association, Philosophy of Science Association, East Lansing, vol. 1, 405-419.

Hofmann, J.R.: 1996, 'Data, Theory, and Evolutionary Phenomena', Origins \& Design 17(2) 6-9. 
Hofmann, J.R. \& Hofmann, P.A.: 1992, 'Darcy's Law and Structural Explanation in Hydrology', in D. Hull, M. Forbes \& K. Okruhlik (eds.), PSA 1992: Proceedings of the 1992 Biennial Meeting of the Philosophy of Science Association, Philosophy of Science Association, East Lansing, vol. $1,23-35$.

International Human Genome Sequencing Consortium: 2001, 'Initial Sequencing and Analysis of the Human Genome', Nature 409, 860-921.

Johnson, P.E.: 1993, Darwin on Trial, (2nd edn), InterVarsity Press, Downers Grove.

Johnson, W.E. \& Coffin, J.M.: 1999, 'Constructing Primate Phylogenies from Ancient Retrovirus Sequences', Proceedings of the National Academy of Sciences 96, 10254-10260.

Kaiser, M.: 1991, 'From Rocks to Graphs', Synthese 89, 111-133.

Kauffman, S.A.: 1993, The Origins of Order: Self-Organization and Selection in Evolution, Oxford University Press, New York.

Kimura, M.: 1968, 'Evolutionary Rate at the Molecular Level', Nature 217, 624-626.

Kimura, M.: 1983, The Neutral Theory of Molecular Evolution, Cambridge University Press, Cambridge.

Kimura, M.: 1987, 'Molecular Evolutionary Clock and the Neutral Theory', Journal of Molecular Evolution 26, 24-33.

King, J.L. \& Jukes, T.H.: 1969, 'Non-Darwinian Evolution', Science 164, 788-798.

King, M.-C. \& Wilson, A.C.: 1975, 'Evolution at Two Levels: Molecular Similarities and Biological Differences Between Humans and Chimpanzees', Science 188, 107-116.

Lamoureux, D.O.: 1999, 'Evangelicals Inheriting the Wind: The Phillip E. Johnson Phenomenon', in P.E. Johnson \& D.O. Lamoureux (eds.), Darwinism Defeated? The Johnson-Lamoureux Debate on Biological Origins, Regent College Publishing, Vancouver, pp. 9-46.

Langly, C.H. \& Fitch, W.M.: 1974, 'An Examination of the Constancy of the Rate of Molecular Evolution', Journal of Molecular Evolution 3, 161-177.

Lewin, R.: 1999, Patterns in Evolution: The New Molecular View, Scientific American Library, New York.

Li, W.-H.: 1997, Molecular Evolution, Sinauer, Sunderland, MA.

Li, W.-H., Gu, Z., Wang, H. \& Nekrutenko, A.: 2001, 'Evolutionary Analysis of the Human Genome', Nature 409, 847-849.

Margoliash, E., Fitch, W.M. \& Dickerson, R.E.: 1969: 'Molecular Expression of Evolutionary Phenomena in the Primary and Tertiary Structures of Cytochrome c', Brookhaven Symposia in Biology 21, 259-305.

Medina, M., Collins, A.G., Silberman, J.D. \& Sogin, M.L.: 2001, 'Evaluating Hypotheses of Basal Animal Phylogeny Using Complete Sequences of Large and Small Subunit rRNA', Proceedings of the National Academy of Sciences 98, 9707-9712.

Miller, K.B.: 1997, 'The Precambrian to Cambrian Fossil Record and Transitional Forms', Perspectives on Science and Christian Faith 49(4), 264-268.

Nikaido, M., Rooney, A.P. \& Okada, N.: 1999, 'Phylogenetic Relationships Among Certariodactyls Based upon Insertions of Short and Long Interspersed Elements: Hippopotamuses are the Closest Extant Relatives of Whales', Proceedings of the National Academy of Sciences 96, 10261-10266.

Padian, K. \& Gishlick, A.: 2002, 'The Talented Mr. Wells', The Quarterly Review of Biology 77, 33-37.

Page, R.D.M. \& Holmes, E.C.: 1998, Molecular Evolution: A Phylogenetic Approach, Blackwell Scientific, Oxford.

Pennock, R.T.: 1999, Tower of Babel: The Evidence Against the New Creationism, The MIT Press, Cambridge.

Perez-Rueda, E. \& Collado-Vides, J.: 2001, 'Common History at the Origin of the Position-Function Correlation in Transcriptional Regulators in Archaea and Bacteria', Journal of Molecular Evolution 53, 17-2-179.

Pigliucci, M.: 2001, 'Intelligent Design Theory’, BioScience 51, 411-414. 
Raff, R.A.: 1996, The Shape of Life: Genes, Development, and the Evolution of Animal Form, University of Chicago Press, Chicago.

Raff, R.A.: 2001, 'The Creationist Abuse of Evo-Devo', Evolution \& Development 3(6), 373-374.

Rudge, D.: 2002, 'Cryptic Designs on the Peppered Moth', International Journal of Tropical Biology and Conservation 50(1), 1-7.

Ruse, M.: 2000, 'Limits to Our Knowledge of Evolution', Evolutionary Biology 32, 3-33.

Salmon, W.C.: 1992, 'Scientific Explanation', in M. Salmon, J. Earman, C. Glymor, J. Lennox, P. Machamer, J.E. McGuire, J. Norton, W. Salmon \& K. Schaffner (eds.), Introduction to the Philosophy of Science, Prentice Hall, Englewood Cliffs, pp. 7-41.

Salzberg, S.L., White, O., Peterson, J. \& Eisen, J.: 2001, 'Microbial Genes in the Human Genome: Lateral Transfer or Gene Loss?', Science 292, 1903-1906.

Schopf, J.W.: 1994, 'The Early Evolution of Life: Solution to Darwin's Dilemma', Trends in Ecology and Evolution 9(10), 375-377.

Schopf, J.W.: 1999, Cradle of Life. The Discovery of the Earth's Earliest Fossils, Princeton University Press, Princeton.

Schwarz, J.H.: 1999, 'Homeobox Genes, Fossils, and the Origin of Species', The Anatomical Record (New Anat.) 257, 15-31.

Scott, E.C.: 2001, 'Fatally Flawed Iconoclasm', Science 292, 2257-2258.

Shubin, N., Tabin, C. \& Carroll, S.: 1997, 'Fossils, Genes and the Evolution of Animal Limbs', Nature 388, 639-648.

Ussery, D.: 2001, 'The Stealth Creationists', Skeptic 8(4), 72-74.

Valentine, J.W, Collins, A.G. \& Meyer, C.P.: 1994, 'Morphological Complexity Increase in Metazoans', Paleontology 20, 131-142.

Valentine, J.W. \& Hamilton, H.: 1998, 'Body Plans, Phyla and Arthropods', in R.A. Fortey \& R.H. Thomas (eds.), Arthropod Relationships, Chapman \& Hall, London, pp. 1-56.

Valentine, J.W., Jablonski, D. \& Erwin, D.H.: 1999, 'Fossils, Molecules and Embryos: New Perspectives on the Cambrian Explosion', Development 126, 851-859.

Van Till, H.J.: 1999, 'The Fully Gifted Creation', in J.P Moreland and J.M. Reynolds (eds.), Three Views on Creation and Evolution, Zondervan, Grand Rapids, pp. 159-218.

Venter, J.C. et al.: 2001, 'The Sequence of the Human Genome', Science 291, 1304-1351.

Wang, D.Y.-C., Kumar, S. \& Blair Hedges, S.: 1999, 'Divergence Time Estimates for the Early History of Animal Phyla and the Origin of Plants, Animals and Fungi', Proceedings of the Royal Society of London Series B 266, 163-171.

Weber, B.H.: 1998, 'Emergence of Life and Biological Selection from the Perspective of Complex Systems Dynamics', in G. Van de Vijver, S.N. Salthe \& M. Delpos (eds.), Evolutionary Systems: Biological and Epistemological Perspectives on Selection and Self-Organization, Kluwer Academic Publishers, Dordrecht, pp. 59-66.

Weber, B.H. \& Depew, D.J.: 2001, 'Developmental Systems, Darwinian Evolution, and the Unity of Science', in S. Oyama, P.E. Griffiths, and R.D. Gray, Cycles of Contingency: Developmental Systems and Evolution, MIT Press, Cambridge MA, pp. 239-253.

Wells, J.: 2000, Icons of Evolutions, Science or Myth? Why Much of What We Teach About Evolution Is Wrong, Regnery, Washington DC.

Wilson, A.C., Carlson, S.S. \& White, T.J.: 1977, 'Biochemical Evolution', Annual Reviews of Biochemistry 46, 573-639.

Woese, C.: 1998, 'The Universal Ancestor', Proceedings of the National Academy of Sciences 95, 6854-6859.

Woese, C.: 2002, 'On the Evolution of Cells', Proceedings of the National Academy of Sciences 99, $8742-8747$.

Woodward, J.: 1989, 'Data and Phenomena', Synthese 79, 393-472.

Zimmer, C.: 2001, Evolution. The Triumph of an Idea, HarperCollins, New York.

Zuckerkandl, E.: 1987, 'On the Evolutionary Clock', Journal of Molecular Evolution 26, 34-46. 
Zuckerkandl, E. \& Pauling, L.: 1965, 'Molecules as Documents of Evolutionary History', Journal of Theoretical Biology 8, 357-366. 